\title{
Cold Energy Utilization in LNG Regasification System Using Organic Rankine Cycle and Trilateral Flash Cycle
}

\author{
Sindu Daniarta1*, Attila R. Imre \\ 1 Department of Energy Engineering, Faculty of Mechanical Engineering, Budapest University of Technology and Economics, \\ H-1521 Budapest, P. O. B. 91, Hungary \\ * Corresponding author, e-mail: sindu.daniarta@edu.bme.hu
}

Received: 15 June 2020, Accepted: 16 September 2020, Published online: 30 September 2020

\begin{abstract}
"Cold energy" refers to a potential to generate power by utilizing the exergy of cryogenic systems, like Liquefied Natural Gas (LNG), using it as the cold side of a thermodynamic cycle, while the hot side can be even on the ambient temperature. For this purpose, the cryogenic Organic Rankine Cycle (ORC) is one type of promising solution with comprehensive benefits to generate electricity. The performance of this cycle depends on the applied working fluid. This paper focuses on the applicability of some natural working fluids and analyzes their performance upon cold energy utilization in the LNG regasification system. An alternative method, the cryogenic Trilateral Flash Cycle (TFC), is also presented here. The selection of working fluid is a multi-step process; the first step uses thermodynamic criteria, while the second one is addressing environmental and safety issues. It will be shown that in LNG regasification systems, single cryogenic ORC performs higher net output power and net efficiency compared to single cryogenic TFC. Propane as working fluid in the single cryogenic ORC generates the highest net output power and net efficiency. It is demonstrated, that concerning 26 novel LNG terminals, a net power output around $320 \mathrm{MW}$ could be recovered from the cold energy by installing a simple cycle, namely a single-step cryogenic ORC unit using propane as working fluid.
\end{abstract}

Keywords

working fluid, cold energy utilization, cryogenic cycle, ORC, TFC

\section{Introduction}

The share of Natural Gas (NG) in the world total primary energy supply was $22.2 \%$ in 2017 [1], slightly below coal $(27.1 \%)$ and oil (32.0\%). Compared to the other two major fossil sources, NG usage emits smaller amounts of pollutants; therefore, its usage is still considered acceptable. $\mathrm{NG}$ is a mixture of saturated light hydrocarbons (mostly methane) that can be delivered through pipelines in gaseous form. It can also be transported and stored in specialized in the liquid-phase as Liquefied Natural Gas (LNG); in this form, it can be transported by special tankers on sea or in special trucks or trains on land.

The process of changing the phase of NG (liquefaction) needs a considerable amount of energy. This process can also be considered as a form of energy storage by creating a cryogenic system with high exergy. The term "cold energy" refers to the potential to create electricity by utilizing the exergy of this cryogenic system, using it as the cold side (heat sink) side of a thermodynamic cycle, while the hot side (heat source) can be the environment on the ambient temperature. LNG is transported in cryogenic vessels where it is stored at ambient pressure and temperature of around $-162{ }^{\circ} \mathrm{C}(111.15 \mathrm{~K})$.

Before being distributed to the market, LNG has to be transformed into the gas through a regasification or vaporization process. At the first stage, LNG is pumped at high pressure. Furthermore, it is vaporized by using several technologies like Open Rack Vaporizer (ORV), Submerged Combustion Vaporizer (SCV), Intermediate Fluid Vaporizer (IFV), and Ambient Air Vaporizer (AAV) [2]. By knowing that amount of cold energy stored in LNG, it can be utilized for many aspects and business, such as air separation [3, 4], seawater desalination [5], carbon dioxide capture $[6,7]$, material freezing for agrofood [8], and even for power generation [9-11].

For power generation, an Organic Rankine Cycle (ORC) can be included in the LNG-regasification system, where seawater or air can be used as a heat source. Due to the unusual range of temperature $\left(-162{ }^{\circ} \mathrm{C}\right.$ to $\left.30{ }^{\circ} \mathrm{C}\right)$, 
the use of two- or three-stage cascade cycles are recommended. García et al. [9] proposed unconventional power plants, which were composed of two cascade Rankine cycles combined with a direct expansion system. In this work, argon and methane are used as working fluid in a closed-loop Rankine cycle. Choi et al. [10] analyzed the three-stage cascade Rankine cycle using propane as a working fluid where the cycle performed the highest net power output, thermal efficiency, and exergy efficiency. Koku et al. [11] identified potential options available for recovery of potential LNG cold energy, which uses propane as a working fluid.

Although some of the halogenated alkanes used as refrigerant seem to be potential working fluid for these cryogenic cycles, the environmental issues related to these materials are strongly limiting their applicability. For that reason, there is a novel trend to find "natural" working fluids, i.e., materials which can also be found in nature, like alkanes, alkenes, or carbon dioxide.

In this paper, we are focusing on pure working fluids; in some cases, a theoretical description would be too difficult with a mixed one. Although the methane content of the LNG is very high, it can be considered as pure one only with some limitation. Due to the presence of additional gases (most often $\mathrm{CO}_{2}$ ), there is a slight change in the evaporation temperature during the evaporation process. Therefore, the usage of non-azeotropic mixtures as working fluid can give better performance [12] than pure one; this should be taken into consideration in further works.

This paper presents the selection of working fluid and analyzes its performance for cryogenic ORC in LNG regasification systems. The simplest model of ORC is chosen to identify and estimate optimal expansion routes from the temperature-entropy characteristic of a working fluid. A comparison of a detailed performance between the selected working fluid (propane) and another possible one (carbon dioxide) is also presented in this work. The selection of working fluid and performance analysis of a slightly different method, the so-called Trilateral Flash Cycle (TFC), introduced by Smith [13], is also shown in the paper.

The structure of this paper is designed as follows: Section 2 describes ORC and TFC systems and boundary conditions. Section 3 explains the selection of working fluid based on a simple ORC model. The main concern in environmental effect, safety, and the thermodynamic condition are served in this work. At the end of this article, Section 4 studies and discusses the model and performance of cold energy utilization, followed by the conclusion of the study.

\section{Simple Organic Rankine Cycle and Trilateral Flash Cycle} ORC is essentially a Rankine cycle using organic working fluid instead of water. A simple ORC has a heat exchanger (HE) for transferring heat from a heat source to cycle, an expander (EXP) (connected to a generator $(\mathrm{G})$, which is not part of the thermodynamic cycle, but necessary for power generation), a condenser (CD) for heat removal, and a pump (PP), all in a closed-loop system. TFC also has the same main equipment as ORC, where the differences between ORC and TFC are the process in the heat exchange. In ORC, the end of heating is in the saturated or supersaturated vapor region, while the heat exchange of TFC is stopped upon reaching the saturated liquid state. Therefore, in ORC (full) vaporization happens during heating (in an isobaric step), while in TFC (partial), vaporization happens upon adiabatic expansion. The condenser of both cycles follows the process of expansion. Both simple ORC or TFC are illustrated in Fig. 1.

Fig. 1 shows that in an LNG vaporization process, simple ORC or TFC can be installed before the LNG vaporizer $\left(E A_{L N G}\right)$, using the condenser $(C D)$ of the cycle as a pre-heater. Thus, the applied cycle utilizes the cold energy of LNG in the condenser to remove heat from the cycle (condenses the fully or partly vaporized working fluid). A typical condenser of TFC has smaller enthalpy change compared to ORC.

The major difference between the two cycles can be seen at the end of heat addition or beginning of the expansion. In TFC, heat addition stops at the saturated liquid phase; i.e., it is without changing the phase of the working fluid.

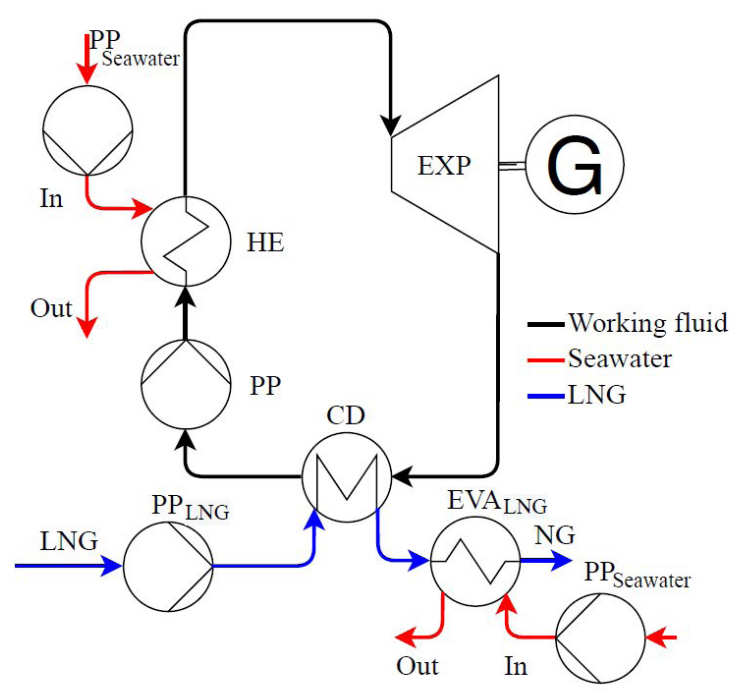

Fig. 1 Schematic layout of simple ORC or TFC cycles in LNG regasification system 
Thus, only sensible heat exists in this cycle. The working fluid in ORC is heated to reach saturated vapor; thus, both latent and sensible heat exist in this cycle. Sensible heat works to increase the temperature of working fluid without changing its phase (only to reach saturated liquid), while latent heat is working to transform its phase from a liquid into the gas phase. For that reason, the heat exchanger of the heat source in ORC can be split into two parts. Sometimes this can be done physically, using two heat exchangers. In other cases, this division is only theoretical, using one, multi-purpose heat exchanger. The first part would be a liquid heater for increasing the temperature of the liquid (with sensible heat) up to the saturated point, while the second would be an evaporator for changing the phase of working fluid by providing the necessary latent heat. Obviously, for TFC, only the liquid heater would be used.

In this system, seawater is used as a heat source at an average temperature of $20^{\circ} \mathrm{C}(293.15 \mathrm{~K})$ and atmospheric pressure. Assuming the fresh seawater is properly cleaned (pre-filtered) to be directly used in the heat exchanger. With this heat source - assuming almost infinite amount one can fix maximal cycle temperature; it was chosen to be fixed at $283 \mathrm{~K}$, while for lowest cycle temperature, three different temperatures were taken ( $153 \mathrm{~K}, 173 \mathrm{~K}$, and $223 \mathrm{~K}$ ), depending on the mass flow rate of $\mathrm{LNG}$ in the condenser.

In this study, the thermodynamic cycles are assumed to be nearly ideal ones. Pressure losses are neglected; therefore, heating/cooling steps are considered to be ideal, isobaric ones. On the other hand, expansion/compression steps are not isentropic, internal efficiencies are considered. Although this loss-free condition is not a realistic assumption, the obtained results can be used to remove unviable scenarios from further considerations and to rank viable ones. The condition in the heat exchanger of heat source and condenser assumes the following: steady-state operating conditions, the change of kinetic and potential energy of the stream are negligible, no heat losses from the heat exchanger, no pressure drop, constant overall heat transfer coefficient, and specific heat. The equation of heat transfer rate $(\dot{Q})$ of heat or cold source and system is defined as follows:

$$
\dot{Q}=\dot{m} \Delta h=\dot{m} c \Delta T,
$$

where $\dot{m}$ represents the mass flow rate and enthalpy change is defined as $\Delta h=h_{\text {in }}-h_{\text {out }}$. The temperature change is described as $\Delta T=T_{\text {in }}-T_{\text {out }}$, and in-out indices are used to mark input and output flows. The pinch-point temperature difference (i.e., the minimum temperature difference upon heating and cooling) is chosen in this case as $5 \mathrm{~K}$.
Obviously, this value can be changed; smaller value would require higher heat exchange area, while higher one would require small heat exchange area.

Initially, the LNG is assumed to be $111.15 \mathrm{~K}$ and atmospheric pressure (i.e., under normal transport conditions). In the end, the regasified methane should be on $7 \mathrm{MPa}$, which is the pressure for long-distance lines in the distribution of NG to the market.

Expander and pump are the vital types of equipment that are used to estimate the amount of gross power generation in the system. The rate of energy $(\dot{W})$ and the efficiency $(\eta)$ of expander and pump are defined as follow:

$$
\begin{aligned}
& \dot{W}_{\text {exp }}=\dot{m}\left(h_{\text {in }}-h_{\text {out }, \text { is }}\right) \eta_{\text {exp }} \\
& \eta_{\text {exp }}\left(h_{\text {in }}-h_{\text {out }, \text { is }}\right)=\left(h_{\text {in }}-h_{\text {out }}\right) \\
& \dot{W}_{p p}=\dot{m}\left(h_{\text {out }, \text { is }}-h_{\text {in }}\right) / \eta_{p p} \\
& \eta_{p p}\left(h_{\text {out }}-h_{\text {in }}\right)=\left(h_{\text {out }, \text { is }}-h_{\text {in }}\right),
\end{aligned}
$$

where $h_{\text {outis }}$ is the output enthalpy in isentropic condition (isentropic is indicated by the subscript of "is"). In this work, the internal efficiencies of the pump and expander are set at 0.7 and 0.8 , respectively.

Since the starting point of expansion of TFC is at the saturated liquid, the expansion of TFC is always in a twophase condition. This condition is the characteristic of TFC compared to ORC. Concerning the expansion process in two-phase, a screw expander or another volumetric-type expander would be recommended to be used [13-15].

Gross power output determines the difference in power consumption of pump and power generation in the closedloop cycle. Net power output calculates the power generations minus the power consumption of the overall pump (LNG pump, seawater pump, and cycle pump). Net output power $\left(P_{\text {net }}\right)$ and efficiency of the system $\left(\eta_{\text {net, system }}\right)$ can be calculated as:

$$
\begin{aligned}
& P_{\text {net }}=\dot{W}_{e x p}-\dot{W}_{p p_{\text {cyle }}}-\dot{W}_{p p_{\mathrm{LNG}}}-\dot{W}_{p p_{\text {seawate }}} \\
& \eta_{\text {net, }, \text { ystem }}=P_{\text {net }} / Q_{i n} .
\end{aligned}
$$

\section{Selection of working fluid}

The choice of working fluid in ORC and TFC is a crucial point to have proper cycle efficiency and power output. Several factors have to be considered in the selection of working fluid which the main selection is based on environmental effect, safety, and thermodynamic condition. 
Concerning the environmental effect, the two major points are Ozone Depletion Potential (ODP) and Global Warming Potential (GWP). ODP is a measure of the degradation of the ozone layer by the given fluid, compared to reference material, trichlorofluoromethane. GWP is a measure of gas contribution for global warming at period time, compared to carbon dioxide. According to environmental issues, materials like chlorofluorocarbons (CFCs), halons, and hydrochlorofluorocarbons (HCFCs) are not considered for working fluid in any further system, most of them have already been forbidden by Montreal and Kyoto Protocols or by the Kigali Amendment or being in the phase-out period.

Safety is described by toxicity and flammability, which refers to safety classification from the American Society of Heating, Refrigerating and Air-Conditioning Engineering (ASHRAE). The thermodynamic condition is described by characteristics of working fluid based on an operating condition, which can be commonly described in temperature - specific entropy or pressure - enthalpy diagrams.

The "major" step of the cycles turning the heat into work is the adiabatic expansion of saturated high-pressure vapor (in ORC) or saturated high-pressure liquid (TFC); therefore working fluids are often classified by their behavior upon expansion as dry (ending the expansion of dry vapor state) or wet (ending the expansion in mixed, wet vapor state). This classification is strongly related to the shape of the phase envelope of the working fluids on the $T-s$ diagram [16-18]. According to the saturated liquid and vapor curve, working fluids are characterized by three-to-five characteristic points [19]. As primary points, A and Z points respectively describe the state corresponding to the lowest temperature on the saturated liquid and vapor curve; physically it is related to the triple point, although for an actual application or a practical, application-related lowest point (like to one related to the temperature of the heat sink) can be taken. $\mathrm{C}$ is the critical point on the $T$-s diagram, while $\mathrm{M}$ and $\mathrm{N}$ (the so-called secondary points, non-existent for wet working fluids) are related to the local entropy maximum and minimum on the saturated vapor line, respectively. This classification helps to determine optimal working fluid based on the point of view of expansion [20].

Upon the selection process, material data are taken from the NIST Chemistry WebBook [21]. Potential fluids for three different maximal-minimal temperature ranges (283-153 K, 283-173 K, and 283-223 K) are shown in the Supplementary Tables S1, S2, and S3.

Tables S1, S2, and S3 show that the propene (CAS No. 115-07-1) has zero ODP and lowest GWP than other materials (excludes carbon dioxide). Additionally - similarly to other alkenes - its chemical stability is not as good as for saturated alkanes, although this is not a major problem for temperatures related to cryogenic applications. Propene is described as ACZ-type, which is the type of wet working fluid. It means that the expansion remains in two-phase if it starts from the saturated vapor. Propane has low toxicity and high flammability. During the installation and operation of the power generation, the leakage is the main concern to avoid ignition caused by propene as a working fluid. This ignition can be avoided by understanding the triangle fire or combustion triangle.

Propane (CAS No. 74-98-6) appears as an alternative working fluid showing slightly better efficiency than propene. Nevertheless, its GPW is higher, but being a "natural" working fluid, it is not forbidden to use it.

Although both the propene and propane are highly flammable, which might be unattractive in a geothermal ORC power plant, in an LNG terminal, this point is probably not as important, being the LNG-terminal well-prepared to handle these kinds of materials. Concerning costs, high-purity alkenes (like propane) are usually more expensive than their saturated counterparts (propane).

The comparison of the phase envelope of propene and propane in temperature-specific entropy diagram is shown in Fig. 2, marking their characteristic points (A, C, and Z). It can be seen that propane has a slightly wider fluid temperature range than propene.

Fig. 3 illustrates the single-step reversible adiabatic expansion process of propane and propene, in the temperature range of 283-173 $\mathrm{K}$. The starting points for the expansions are saturated vapor states. Although the starting and ending conditions (temperature and entropy values) are almost identical, the different shapes of the two-phase envelopes cause a measurable difference in the cycle performances.

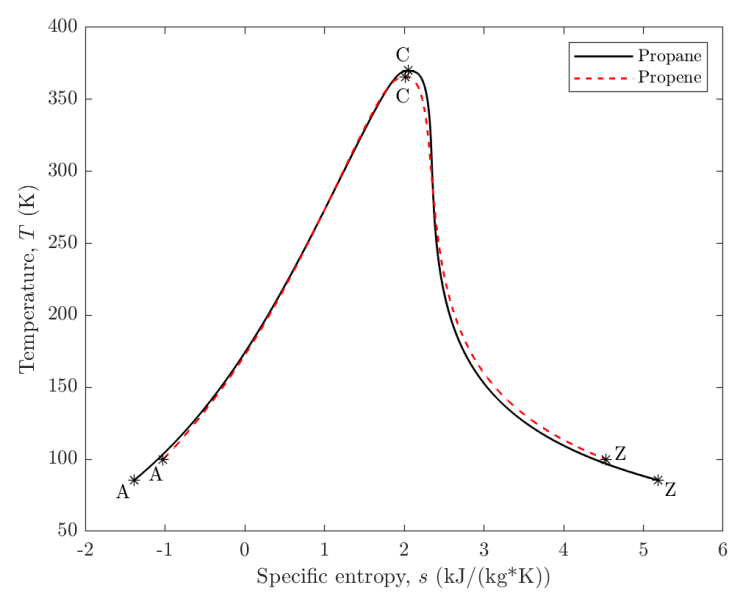

Fig. 2 Propene and propane in temperature-specific entropy diagram 


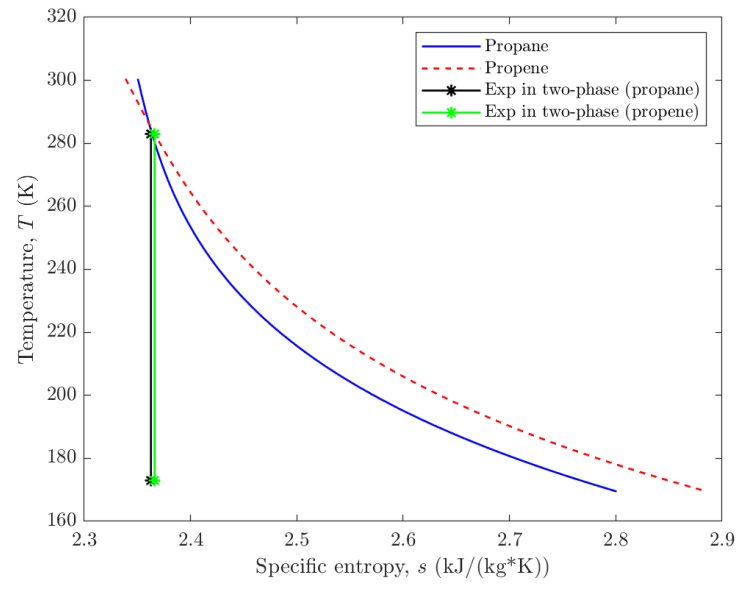

Fig. 3 Single-step reversible adiabatic expansion of propane and propane, starting from saturated vapor state at $283 \mathrm{~K}$ and ending at $173 \mathrm{~K}$ in a mixed vapor-liquid state

The quality (fraction of vapor phase) during and at the end process of expansion is also an important measurement for the expansion and total performance. For example, it can influence the internal efficiency and lifetime of the expander. The range of qualities upon expansion is shown in Tables S1, S2, and S3. If the quality is too low ( $x=1$ means saturated or dry vapor, while $x=0$ is describing purely liquid phase), so-called droplet erosion can exist. The vapor quality can be increased by decreasing the internal efficiency of the expander; in this case, the expansion line would be tilted, and the low-temperature end-point would go to higher entropies. Even it is possible to reach a saturated vapor phase by having sufficiently low expander-efficiency [22-24]; in this case, the problem caused by droplet erosion would be solved at the cost of some losses in cycle efficiency. A novel method has been established to evaluate the internal efficiency of the hypothetical expander inserted into the cycle to start and end expansion on the saturated vapor curve [24]. In this way, droplet erosion would be minimized; these hypothetical expander efficiencies are shown in the last columns of Tables S1, S2, and S3 for three different maximal and minimal cycle temperature pairs. In all, the three cryogenic temperature ranges, propane out-performs propene in this criterion because higher hypothetical expander efficiency values would lead to a smaller final loss in net efficiency.

A recently more and more popular candidate of working fluid for low-temperature cycles is the carbon dioxide [25]. For that reason, this work is also going to compare it to propane. Carbon dioxide (CAS No. 124-38-9) is an ACZ-type of working fluid (the same as propene and propane). With relatively low GWP $(\mathrm{GWP}=1)$ and with zero ODP, it can be used as an alternative of propane in cryogenic ORC and TFC. This material is abundant and affordable to use as a working fluid in a cryogenic power plant. The saturation curves of carbon dioxide and propane in temperature-specific entropy space are shown in Fig. 4.

Fig. 4 shows that the fluid range (i.e., the range, where the liquid and vapor phases co-exist and the material at least theoretically - can be used as working fluid) is much smaller for carbon dioxide than for propane (or propene); therefore it could be used only in the highest temperature range (223-283 K).

Both materials have the characteristic of ACZ-type of a working fluid, where the expansion always works under two-phase if it starts from the saturated vapor. Carbon dioxide has a limited operating temperature range, which it cannot work under $216.59 \mathrm{~K}$ due to freezing point. However, carbon dioxide has an applicable temperature range up to $2000 \mathrm{~K}$ as a working fluid. Carbon dioxide, as a working fluid, is used as a comparison in designing cryogenic ORC and TFC, which is presented in Section 4.

\section{Results and discussion}

The design of single cryogenic ORC and TFC is already illustrated in Fig. 1, where it uses seawater as a heat source and LNG as a cooling source. The heat exchanger of ORC in Fig. 1 is split into a liquid heater and an evaporator. Liquid heater works to increase the temperature of working fluid in a liquid phase to reach saturated liquid state (without changing the phase) while the evaporator is operating to change the working fluid from a liquid into the vapor phase.

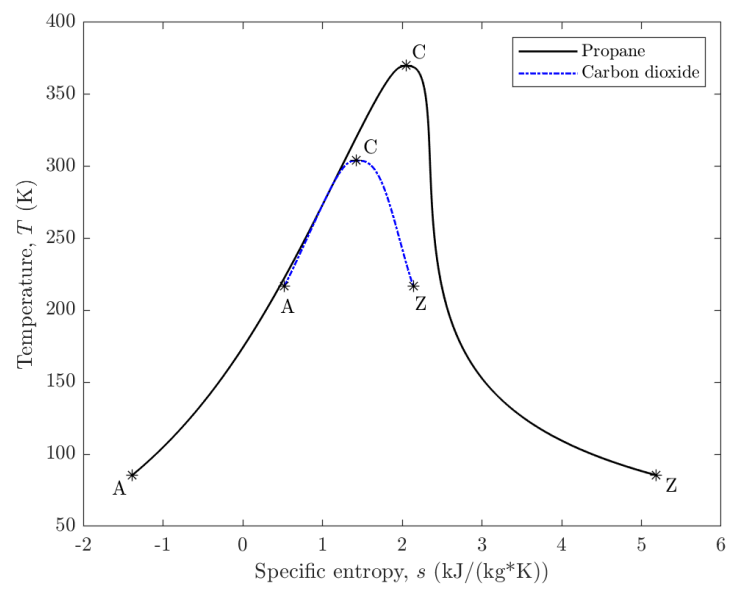

Fig. 4 Propane and carbon dioxide in the temperature-specific entropy diagram 
The minimal and maximal cycle temperature for the comparison between carbon dioxide and propane cycles are set as $216.59 \mathrm{~K}$ and $283.15 \mathrm{~K}$, respectively. The lower temperature is defined by the freezing point of carbon dioxide. The performance of single cryogenic TFC and ORC based on the same mass flow rate of LNG is given in Table 1, where the HE (LIQ) and HE (EVA) are the two "heating" heat exchangers (liquid heater and evaporator, respectively).

Table 1 shows the characteristic of single cryogenic ORC and TFC. In both cases, the performances are significantly affected by the mass flow rate of working fluid (by using a constant mass flow rate of LNG). The mass flow rate of working fluid for TFC is relatively higher than ORC. It is caused by the different heat transfer in the heat exchanger of a heat source. TFC only absorbs heat to increase the temperature of liquid without changing the phase (i.e., needs to cover only the sensible heat), while the condition is different in ORC, where a high amount of latent heat should also be covered from the external source. The mass flow rate is a crucial point in the cycle where it will influence the own power consumption. The mass flow rate is crucial concerning the layout of the equipment.

For the same mass flow rate of seawater, the TFC generates higher net output power compared to ORC [26]. Nevertheless, the purpose of cold energy utilization in this work is to compare the performance of both cycles as a result of the same mass flow rate of $\mathrm{LNG}$, since in this case, the LNG is the source for energy production. Table 1 describes that single cryogenic ORC using propane

Table 1 Performance of single cryogenic ORC and TFC

\begin{tabular}{|c|c|c|c|c|c|}
\hline \multirow[b]{2}{*}{ Process } & \multirow[b]{2}{*}{ Unit } & \multicolumn{2}{|c|}{ ORC } & \multicolumn{2}{|c|}{$\mathrm{TFC}$} \\
\hline & & Propane & $\begin{array}{l}\text { Carbon } \\
\text { dioxide }\end{array}$ & Propane & $\begin{array}{l}\text { Carbon } \\
\text { dioxide }\end{array}$ \\
\hline HE (LIQ) & $\Delta h(\mathrm{~kJ} / \mathrm{kg})$ & 133.643 & 121.326 & 133.643 & 121.326 \\
\hline HE (EVA) & $\Delta h(\mathrm{~kJ} / \mathrm{kg})$ & 360.280 & 197.160 & - & - \\
\hline EXP & $\Delta h(\mathrm{~kJ} / \mathrm{kg})$ & 70.128 & 45.440 & 12.552 & 13.928 \\
\hline CD & $\Delta h(\mathrm{~kJ} / \mathrm{kg})$ & 425.145 & 277.693 & 122.441 & 112.045 \\
\hline$P$ & $\Delta h(\mathrm{~kJ} / \mathrm{kg})$ & 1.350 & 4.647 & 1.350 & 4.647 \\
\hline$P_{s w}$ & $\Delta h(\mathrm{~kJ} / \mathrm{kg})$ & 0.069 & 0.069 & 0.069 & 0.069 \\
\hline$P_{\mathrm{LNG}}$ & $\Delta h(\mathrm{~kJ} / \mathrm{kg})$ & 33.129 & 33.129 & 33.129 & 33.129 \\
\hline$\dot{m}_{w f}$ & $\mathrm{~kg} / \mathrm{s}$ & 1.300 & 1.991 & 4.515 & 4.935 \\
\hline$\dot{m}_{s w}$ & $\mathrm{~kg} / \mathrm{s}$ & 22.312 & 18.694 & 9.593 & 9.517 \\
\hline$\dot{m}_{\mathrm{LNG}}$ & $\mathrm{kg} / \mathrm{s}$ & 1 & 1 & 1 & 1 \\
\hline$\eta_{\text {net,cycle }}$ & $\%$ & 8.529 & 7.382 & 2.783 & 2.007 \\
\hline$P_{\text {net }}$ & $\mathrm{kW}$ & 54.783 & 46.808 & 16.796 & 12.015 \\
\hline
\end{tabular}

generates the highest net output power of $54.783 \mathrm{~kW}$ and net efficiency of the cycle of $8.529 \%$. In both cycles, carbon dioxide yields lower net output power and net efficiency compared to propane.

The four variants (propane TFC, propane ORC, carbon dioxide TFC and carbon dioxide ORC) listed in Table 1 are shown in Fig. 5 with various LNG mass flow rates to know the potential of power generation by using single cryogenic ORC or TFC in the current LNG regasification system.

All variants generate positive net output power, which means that the power consumption of the LNG pump can be covered. According to this result, the installation of single cryogenic ORC or TFC based power plants in the LNG regasification system can help to reduce operation cost by significantly reducing power consumption.

Fig. 5 can be used to represent the potential of cold energy utilization in further coastal LNG regasification projects. There are $26 \mathrm{LNG}$ regasification systems under construction, according to the database of the International Gas Union (IGU) [27]. The factor of operational capacity for each LNG regasification system is assumed to be $85 \%$, which means 7446 running hours in a year. By using this assumption, the average mass flow rate for the maximum capacity condition can be determined. This mass flow rate of LNG is used as a basis in the calculation of the net power output of the cycle. Table 1 and Fig. 5 show that single cryogenic ORC using propane out-performs the other ones in the cold energy utilization. Thus, a cryogenic ORC power plant with propane as a working fluid would be a promising add-on for existing, as well as upcoming LNG terminals. The potential of the net output power of cold energy utilization using single cryogenic ORC (propane) for novel LNG receiving terminals

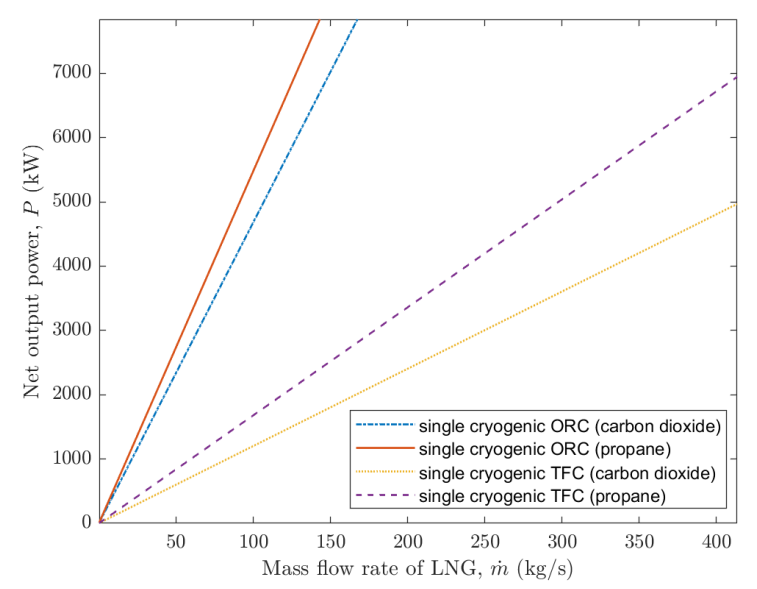

Fig. 5 Performance of single cryogenic ORC and TFC using propane or carbon dioxide 
Table 2 Potential of the net output power of single cryogenic ORC using propane in the upcoming LNG regasification system (2020-2023)

\begin{tabular}{|c|c|c|c|c|}
\hline Market & Terminal & $\begin{array}{l}\text { Capacity } \\
\text { (MTPA) }\end{array}$ & $\begin{array}{l}\mathrm{Max} \\
\dot{m}_{\mathrm{LNG}} \\
(\mathrm{kg} / \mathrm{s})\end{array}$ & $\begin{array}{c}P_{\text {net }} \\
(\mathrm{MW})\end{array}$ \\
\hline India & Jafrabad & 5 & 186.53 & 17.01 \\
\hline Russia & Kaliningrad & 2.7 & 100.73 & 9.19 \\
\hline Bahrain & Bahrain & 6 & 223.83 & 20.41 \\
\hline India & H-Gas Gateway & 4 & 149.22 & 13.61 \\
\hline Brazil & Acu Port & 5.6 & 208.91 & 19.05 \\
\hline Ghana & Ghana & 2 & 74.61 & 6.08 \\
\hline China & $\begin{array}{l}\text { Chaozhou } \\
\text { Huafeng }\end{array}$ & 1 & 37.31 & 3.40 \\
\hline United States & New Fortress & 0.5 & 18.65 & 1.70 \\
\hline Mexico & New Fortress & 3 & 111.92 & 10.21 \\
\hline Turkey & Gulf of Saros & 5.4 & 201.45 & 18.37 \\
\hline Philippines & Pagbilao & 3 & 111.92 & 10.21 \\
\hline Croatia & Krk & 1.9 & 70.88 & 6.46 \\
\hline Kuwait & $\begin{array}{c}\text { Kuwait } \\
\text { Permanent }\end{array}$ & 22 & 802.72 & 74.85 \\
\hline China & Wenzhou & 3 & 111.92 & 10.21 \\
\hline India & Dhamra & 5 & 186.53 & 17.01 \\
\hline El Salvador & El Salvador & 0.5 & 18.65 & 1.70 \\
\hline Indonesia & $\begin{array}{c}\text { Cimalaya- } \\
\text { Jawa } 1\end{array}$ & 2.4 & 89.53 & 8.17 \\
\hline China & Binhai & 3 & 111.92 & 10.21 \\
\hline Cyprus & Cyprus & 0.6 & 22.38 & 2.04 \\
\hline Thailand & Nong Fab & 7.5 & 279.79 & 25.52 \\
\hline Japan & Niihama & 0.5 & 18.65 & 1.70 \\
\hline India & Chhara & 5 & 186.53 & 17.01 \\
\hline Vietnam & Thi Vai & 1 & 37.31 & 3.40 \\
\hline China & Zhangzhou & 3 & 111.92 & 10.21 \\
\hline China & Yueyang & 2 & 74.61 & 6.80 \\
\hline China & Yangjiang & 2 & 74.61 & 6.80 \\
\hline Total & & 97.6 & - & 332.06 \\
\hline
\end{tabular}

planned for 2020-2023 is given in Table 2, where MTPA is a million tonnes per annum.

Table 2 shows the potentially recoverable power from cold energy utilization in the upcoming LNG terminal in 2020-2023, assuming the single cryogenic ORC uses propane installed in the main pipeline of the LNG regasification system (before LNG vaporizer). The LNG terminal under construction in 2020-2023 has a total capacity of

\section{References}

[1] International Energy Agency "Key World Energy Statistics 2019", IEA, Paris, France, 2019.

[2] Mokhatab, S., Mak, J. Y., Valappil, J. V., Wood, D. A. "Handbook of Liquefied Natural Gas", Gulf Professional Publishing, Oxford, United Kingdom, 2013.
97.6 MTPA, therefore adding single cryogenic ORC units using propane as working fluid for each terminal can generate approximately $332 \mathrm{MW}$.

\section{Conclusion}

The proportion of LNG in the global gas market is steadily increasing, being LNG a relatively easily transportable fuel with high energy density. More and more LNG terminals are built to provide alternative commercial routes for NG; in those terminals, LNG should be regasified before entering local gas-network. Upon regasification, part of the so-called "cold energy" (the exergy related to ambient condition) can be recovered for power generation with the help of a single-step cryogenic ORC or TFC. In this paper, the possibility of using these cycles with a properly chosen working fluid has been discussed. Several working fluids have been analyzed in the pre-filtering process, based on their physical, chemical, and environmental (like GWP and ODP) properties. For further analysis, three fluids were chosen, propane, propene, and carbon dioxide. According to the result of this work, the highest net output power could be realized with simple ORC using propane a widely available saturated alkane - as working fluid.

Finally, an estimate for recoverable net power was given by assuming the use of simple cryogenic propane-ORC cycle-based small power plants on all LNG receiving terminals under construction and finalized between 2020 and 2023. Assuming 97.6 MTPA (million tonnes per annum) of LNG capacity, the total recoverable power for the 26 new LNG terminals is around $320 \mathrm{MW}$, varying between 1.7 MW (for example, for the LNG terminal Niihama, Japan) to $75 \mathrm{MW}$ (Kuwait Permanent LNG Import Facility). Even smaller terminals, like the floating LNG receiving terminal in Krk, Croatia, serving mostly the need of Croatia and Hungary, 6.5 MW power can be recovered.

\section{Acknowledgement}

This work was performed in the frame of the FIEK_161-2016-0007 project, implemented with the support provided from the National Research, Development and Innovation Fund of Hungary, financed under the FIEK_16 funding scheme.

[3] Mehrpooya, M., Sharifzadeh, M. M. M., Rosen, M. A. "Optimum design and exergy analysis of a novel cryogenic air separation process with LNG (liquefied natural gas) cold energy utilization", Energy, 90(2), pp. 2047-2069, 2015. https://doi.org/10.1016/j.energy.2015.07.101 
[4] Mehrpooya, M., Kalhorzadeh, M., Chahartaghi, M. "Investigation of novel integrated air separation processes, cold energy recovery of liquefied natural gas and carbon dioxide power cycle", Journal of Cleaner Production, 113, pp. 411-425, 2016.

https://doi.org/10.1016/j.jclepro.2015.12.058

[5] Williams, P. M., Ahmad, M., Connolly, B. S., Oatley-Radcliffe, D. L. "Technology for freeze concentration in the desalination industry", Desalination, 356, pp. 314-327, 2015.

https://doi.org/10.1016/j.desal.2014.10.023

[6] Tuinier, M. J., van Sint Annaland, M., Kramer, G. J., Kuipers, J. A. M. "Cryogenic $\mathrm{CO}_{2}$ capture using dynamically operated packed beds", Chemical Engineering Science, 65(1), pp. 114-119, 2010. https://doi.org/10.1016/j.ces.2009.01.055

[7] Zhao, L., Dong, H., Tang, J., Cai, J. "Cold energy utilization of liquefied natural gas for capturing carbon dioxide in the flue gas from the magnesite processing industry", Energy, 105, pp. 45-56, 2016. https://doi.org/10.1016/j.energy.2015.08.110

[8] Messineo, A., Giuseppe, P. "LNG cold energy use in agro-food industry: A case study in Sicily", Journal of Natural Gas Science and Engineering, 3(1), pp. 356-363, 2011.

https://doi.org/10.1016/j.jngse.2011.02.002

[9] García, R. F., Carril, J. C., Gomez, J. R., Gomez, M. R. "Combined cascaded Rankine and direct expander based power units using LNG (liquefied natural gas) cold as heat sink in LNG regasification", Energy, 105, pp. 16-24, 2016.

https://doi.org/10.1016/j.energy.2015.09.051

[10] Choi, I.-H., Lee, S., Seo, Y., Chang, D. "Analysis and optimization of cascade Rankine cycle for liquefied natural gas cold energy recovery", Energy, 61, pp. 179-195, 2013.

https://doi.org/10.1016/j.energy.2013.08.047

[11] Koku, O., Perry, S., Kim, J. K. "Techno-economic evaluation for the heat integration of vaporization cold energy in natural gas processing", Applied Energy, 114, pp. 250-261, 2014. https://doi.org/10.1016/j.apenergy.2013.09.066

[12] Invernizzi, C. M., Iora, P. "The exploitation of the physical energy of liquid natural gas by closed power thermodynamic cycles. An overview", Energy, 105, pp. 2-15, 2016. https://doi.org/10.1016/j.energy.2015.09.020

[13] Smith, I. K. "Development of the Trilateral Flash Cycle System: Part 1: Fundamental Considerations", Proceedings of the Institution of Mechanical Engineers, Part A: Journal of Power and Energy, 207(3), pp. 179-194, 1993. https://doi.org/10.1243/PIME_PROC_1993_207_032_02

[14] Kolasiński, P. "The Method of the Working Fluid Selection for Organic Rankine Cycle (ORC) Systems Employing Volumetric Expanders", Energies, 13(3), Article number: 573, 2020. https://doi.org/10.3390/en13030573

[15] Zhang, X., Zhang, Y., Cao, M., Wang, J., Wu, Y., Ma, C. "Working Fluid Selection for Organic Rankine Cycle Using Single-Screw Expander", Energies, 12(16), Article number: 3197, 2019. https://doi.org/10.3390/en12163197
[16] Chen, H., Goswami, D. Y., Stefanakos, E. K. "A review of thermodynamic cycles and working fluids for the conversion of lowgrade heat", Renewable and sustainable energy reviews, 14(9), pp. 3059-3067, 2010.

https://doi.org/10.1016/j.rser.2010.07.006

[17] Garrido, J. M., Quinteros-Lama, H., Mejía, A., Wisniak, J., Segura, H. "A rigorous approach for predicting the slope and curvature of the temperature-entropy saturation boundary of pure fluids", Energy, 45(1), pp. 888-899, 2012. https://doi.org/10.1016/j.energy.2012.06.073

[18] White, J. A., Velasco, S. "Characterizing wet and dry fluids in temperature-entropy diagrams", Energy, 154, pp. 269-276, 2018. https://doi.org/10.1016/j.energy.2018.04.105

[19] Györke, G., Deiters, U. K., Groniewsky, A., Lassu, I., Imre, A. R. "Novel classification of pure working fluids for Organic Rankine Cycle", Energy, 145, pp. 288-300, 2018. https://doi.org/10.1016/j.energy.2017.12.135

[20] Imre, A. R., Kustán, R., Groniewsky, A. "Thermodynamic Selection of the Optimal Working Fluid for Organic Rankine Cycles", Energies, 12(10), Article number: 2028, 2019. https://doi.org/10.3390/en12102028

[21] NIST "NIST Standard Reference Database Number 69", In: NIST Chemistry WebBook, National Institute of Standards and Technology, U.S. Department of Commerce, Washington, DC, USA, 2018. https://doi.org/10.18434/T4D303

[22] Imre, A. R., Kustán, R., Groniewsky, A. "Thermodynamic Selection of the Optimal Working Fluid", In: $5^{\text {th }}$ International Seminar on ORC Power Systems, Athens, Greece, 2019, Paper ID: 156. [online] Available at: https://www.orc2019.com/online/ proceedings/documents/156.pdf [Accessed: 10 May 2020]

[23] Shahrooz, M., Lundqvist, P., Nekså, P. "Effect of Working Fluid Type on Low Temperature Rankine Cycle Optimization", In: $5^{\text {th }}$ International Seminar on ORC Power Systems, Athens, Greece, 2019, Paper ID: 197. [online] Available at https://www.orc2019.com/ online/proceedings/documents/197.pdf [Accessed: 10 May 2020]

[24] Kustán, R., Imre, A. R., Groniewsky, A. "The effect of internal efficiency of expander on the working fluid selection", In: IIR Rankine 2020 International Conference - Advances in Cooling, Heating and Power Generation, Glasgow, United Kingdom, 2020, Paper ID: 1170 .

https://doi.org/10.18462/iir.rankine.2020.1170

[25] Angelino, G., Invernizzi, C. M. "Carbon dioxide power cycles using liquid natural gas as heat sink", Applied Thermal Engineering, 29(14-15), pp. 2935-2941, 2009. https://doi.org/10.1016/j.applthermaleng.2009.03.003

[26] Daniarta, S. "Suitable Technique and Working Fluid for Cold Energy Utilization in LNG Regasification System", MSc Thesis, Budapest University of Technology and Economics, 2020.

[27] International Gas Union "2020 World LNG Report", [online] Available at: https://www.igu.org/sites/default/files/nodedocumen t-field_file/2020\%20World\%20LNG\%20Report.pdf [Accessed: 31 May 2020] 